\title{
Carbon Cloth Modified Electrode for the Rapid PB Detection in Water
}

\author{
Yuxi Zhang ${ }^{1}$, Jingtao Liu $^{2 *}$, Fengchun Yang ${ }^{3}$ \\ ${ }^{I}$ The Institute of Hydrogeology and Environmental Geology, Chinese Academy of Geological Sciences, \\ China. \\ ${ }^{2}$ Key Laboratory of Groundwater Contamination and Remediation, China Geological Survey \& Hebei \\ Province, Shijiazhuang 050061, China. \\ ${ }^{3}$ Northwest University, China. \\ *Corresponding Author.
}

\begin{abstract}
Through simple high-temperature hydrothermal treatment of carbon cloth, a hoCCE electrochemical sensor was prepared for detecting $\mathrm{Pb}^{2+}$. After hydrothermal treatment, the carbon cloth surface has more ketone-based sites and defects, which improves the electrochemical active area, conductivity and detection sensitivity, and strengthens the catalytic performance of $\mathrm{Pb}^{2+}$. Under optimal conditions, the current concentration curve was obtained by differential pulse anodic stripping voltammetry, with linear range $0.06-1.6 \mu M$, regression equation $I p(m A)=0.03208+0.12843 \mathrm{C}(\mu \mathrm{M})$, and detection limit $30 \mathrm{nM}$. The resulting sensor was applied to detect $\mathrm{Pb}^{2+}$ in real-life water samples. Compared with other studies, hoCCE enjoys advantages in linear interval detection, cost, preparation procedure, and vulnerability.
\end{abstract}

Keywords: Hydrothermal carbon cloth, differential pulse anodic stripping voltammetry, electrochemical detection, portable detection, $\mathrm{Pb}^{2+}$

\section{Introduction}

As a common heavy metal, lead $(\mathrm{Pb})$ is mainly distributed in the environment in the form of compound [1]. With the development of human industrialization, pollution emissions from industries such as chemicals, coatings, shallow exhaust gas, and metal smelting have led to a gradual increase of lead accumulation in the environment [2]. Lead can cause great harm to human health [3]. After ingested by the human body, lead will bond with proteins and enzymes in the body, causing acute or chronic poisoning. Moreover, there is a risk of carcinogenesis and mutagenesis [4]. The WHO stipulates that the standard value of lead in drinking water is $0.01 \mathrm{mg} \cdot \mathrm{L}^{-1}$, and the EPA requires that no lead should be detected in drinking water [5].

In pollution incident investigation and water quality monitoring, rapid on-site detection plays a very critical role [6]. Thus, to protect the environment, rapidity and sensitiveness of electrochemical methods, it is of practical significance to prepare an electrochemical sensor for real-life on-site $\mathrm{Pb}^{2+}$ detection in water [7]. In traditional electrochemical analysis, a glassy carbon electrode is generally used as the working electrode, but its performance is intermediate. To enhance the analysis performance, the commonly used strategy is to modify the glassy carbon electrode surface with metal composite nanomaterials. However, metal composite nanomaterials have complicated synthesis process, low stability, and physiological toxicity, so its practical application is not easy. Whereas, carbon materials enjoys broader application prospect in sensor construction.

In this study, a carbon cloth electrode was used as the sensor substrate. Without adding other catalysts, the bare carbon cloth was modified by hydrothermal treatment to increase its active surface area and active sites. The obtained hydrothermal carbon cloth (hoCC) was used as a working electrode to construct an electrochemical sensor for $\mathrm{Pb}^{2+}$ detection. The paper analyzes the influence of experimental conditions; and uses DPASV to obtain the current concentration curve and determine the detection limit of the linear range. Finally, electrode stability and anti-interference were tested for successful use in the water sample $\mathrm{Pb}^{2+}$ detection.

ISSN: 0010-8189

(C) CONVERTER 2020 


\section{Materials and methods}

\subsection{Reagents and materials}

Carbon cloth was purchased from Taiwan Carbon Energy Chemical Co., Ltd.; glassy carbon electrode (CHI102), $\mathrm{Al}_{2} \mathrm{O}_{3}$ polishing powder $(0.05 \mu \mathrm{m}, 1.0 \mu \mathrm{m})$ were purchased from Shanghai Chenhua Instrument Co., Ltd.; other reagents $\mathrm{CH}_{3} \mathrm{COONa}(\mathrm{NaAc}), \mathrm{CH}_{3} \mathrm{COOH}(\mathrm{HAc}),\left(\mathrm{CH}_{3} \mathrm{COO}\right)_{2} \mathrm{~Pb}\left(\mathrm{~Pb}(\mathrm{Ac})_{2}\right), \mathrm{KCl}, \mathrm{K}_{3}\left[\mathrm{Fe}(\mathrm{CN})_{6}\right], \mathrm{K}_{4}\left[\mathrm{Fe}(\mathrm{CN})_{6}\right]$, acetone, and ethanol were acquired from Xi'an Jingbo Biotechnology Co., Ltd. All of them were analytically pure without further purification.

$0.1 \mathrm{M}$ acetate buffer served as an electrolyte. The preparation method is to first measure $11.5 \mathrm{~mL}$ glacial acetic acid and mixing it with $1 \mathrm{~L}$ of ultrapure water to obtain $0.2 \mathrm{M}$ HAc solution; dilute $16.4 \mathrm{~g}$ anhydrous sodium acetate with ultrapure water to $1000 \mathrm{~mL}$, set the volume to obtain $0.2 \mathrm{M} \mathrm{NaAc}$ solution; finally, pipette a certain amount of $0.2 \mathrm{M} \mathrm{HAc}$ and $0.2 \mathrm{M} \mathrm{NaAc}$, mix according to the required $\mathrm{pH}$ value to obtain $0.1 \mathrm{M}$ acetate buffer with different $\mathrm{pH}$ values. The preparation method of the $\mathrm{Pb}^{2+}$ standard sample is to accurately weigh the lead acetate solid and dissolve it with $20 \mathrm{~mL}$ ultrapure water, and set the volume to $100 \mathrm{~mL}$. Electrochemical impedance mapping analysis was conducted using $0.1 \mathrm{M} \mathrm{KCl}$ containing $5 \mathrm{mM}\left[\mathrm{Fe}(\mathrm{CN})_{6}\right]^{3-/ 4-}$, which was prepared using deionized water (with the resistance above $18.3 \mathrm{M} \Omega \cdot \mathrm{cm}$ ) prepared using Millipore system.

\subsection{Electrode modification}

Before the experiment, the bare carbon cloth electrode was ultrasonically cleaned in acetone, ethanol, and water for $15 \mathrm{~min}$, followed by vacuum-drying. Finally, it was cut into small $1.0 \times 2.0 \mathrm{~cm}$ rectangles for later use. For the hydrothermal carbon cloth electrode, based on this, the pretreated carbon was placed in a polytetrafluoroethylene autoclave, added with secondary water for hydrothermal reaction overnight at $180^{\circ} \mathrm{C}$ to obtain hydrothermal $\mathrm{CC}$ (hoCC). Then use secondary water and ethanol to ultrasonically clean for 1 minute, and then dry in a vacuum drying oven to complete the modification. The bare glassy carbon electrode ( $3 \mathrm{~mm}$ in diameter), used for comparison, was polished with 0.05 and $1.0 \mu \mathrm{m}$ polishing alumina before use and thoroughly cleaned for later use.

\subsection{Electrochemical test}

Use SEM (Hitachi S-4800 Scanning Electron Microscope) to analyze the material morphological characteristics, record Raman spectrum (Horiba Jobin Yvon LabRAM HR800, France) under $633 \mathrm{~nm}$ laser excitation to analyze molecular structure, and use XPS (ULVAC-PHI 5000 Versaprobe II X-ray photoelectron spectrometer, Japan) to analyze the material composition.

Electrochemical measurements were conducted by Chenhua CHI 660D electrochemical workstation equipped with a three-electrode system consisting of $1 \times 2 \mathrm{~cm}$ carbon cloth electrode $(1.0 \mathrm{~cm} \times 2.0 \mathrm{~cm})$, saturated $\mathrm{Ag} / \mathrm{AgCl}$ electrode and $\mathrm{Pl}$ wire as the working, reference and auxiliary electrodes, respectively.

$\mathrm{CV}$ and EIS curves were carried out $0.1 \mathrm{M} \mathrm{KCl}$ containing $5 \mathrm{mM}\left[\mathrm{Fe}(\mathrm{CN})_{6}\right]^{3-14-}$. Where $\mathrm{CV}$ method has potential $0.2-0.6 \mathrm{~V}$, scanning rate $50 \mathrm{mV} \cdot \mathrm{s}^{-1}$, EIS frequency range was $0.1-100000 \mathrm{~Hz}$, and AC probe amplitude $50 \mathrm{mV}$. DPASV was used for electrochemical detection and analysis. The signal parameters were amplitude $25 \mathrm{mV}$, incremental potential $4 \mathrm{mV}$, and frequency $15 \mathrm{~Hz}$. The experiment had acetate buffer (with $\mathrm{pH}=4.5$ ) as the electrolyte, $-1.0 \mathrm{~V}$ deposition potential, and $160 \mathrm{~s}$ deposition duration. All tests were performed at room temperature.

\section{Results and discussion}

3.1 Material characterization

ISSN: 0010-8189

(C) CONVERTER 2020 
SEM is a common method for observing the microscopic morphological characteristics of materials. The surface morphological characteristics of the tested substance were obtained by transforming and imaging the physical information excited by the high-energy electron beam scanning material. Compared with $\mathrm{CC}$, the hoCC image did not change significantly (see Figure $1 \mathrm{~A}$ and 1B), indicating that the hydrothermal step did not change the shapes and structures of the CC textiles.

The high-resolution XPS C 1s spectrum of hoCC and CC (Figure 1C) showed peaks belonging to $\mathrm{C}=\mathrm{C}, \mathrm{C}-\mathrm{O}$, and $\mathrm{C}=\mathrm{O}$ bonds at 284.6, 285.3, and 288.1 eV, respectively [8]. It can be observed that after the hydrothermal step, the peak corresponding to the $\mathrm{C}-\mathrm{O}$ bond decreased from $24.70 \%$ to $21.90 \%$, while the $\mathrm{C}=\mathrm{O}$ bond peak increased from $9.4 \%$ to $10.4 \%$. Previous studies have shown [9] that ketone $(\mathrm{C}=\mathrm{O})$ sites contribute a lot to the electrochemical activity of carbon nanomaterials, which will create the same effect in hoCC.

In Figure 1D, the higher $\mathrm{I}_{\mathrm{D}} / \mathrm{I}_{\mathrm{G}}$ value of hoCC also indicates higher degree of defects and more easily conducted electrons. Combined with XPS results, both reflect that treated carbon cloth has higher electrochemical activity.
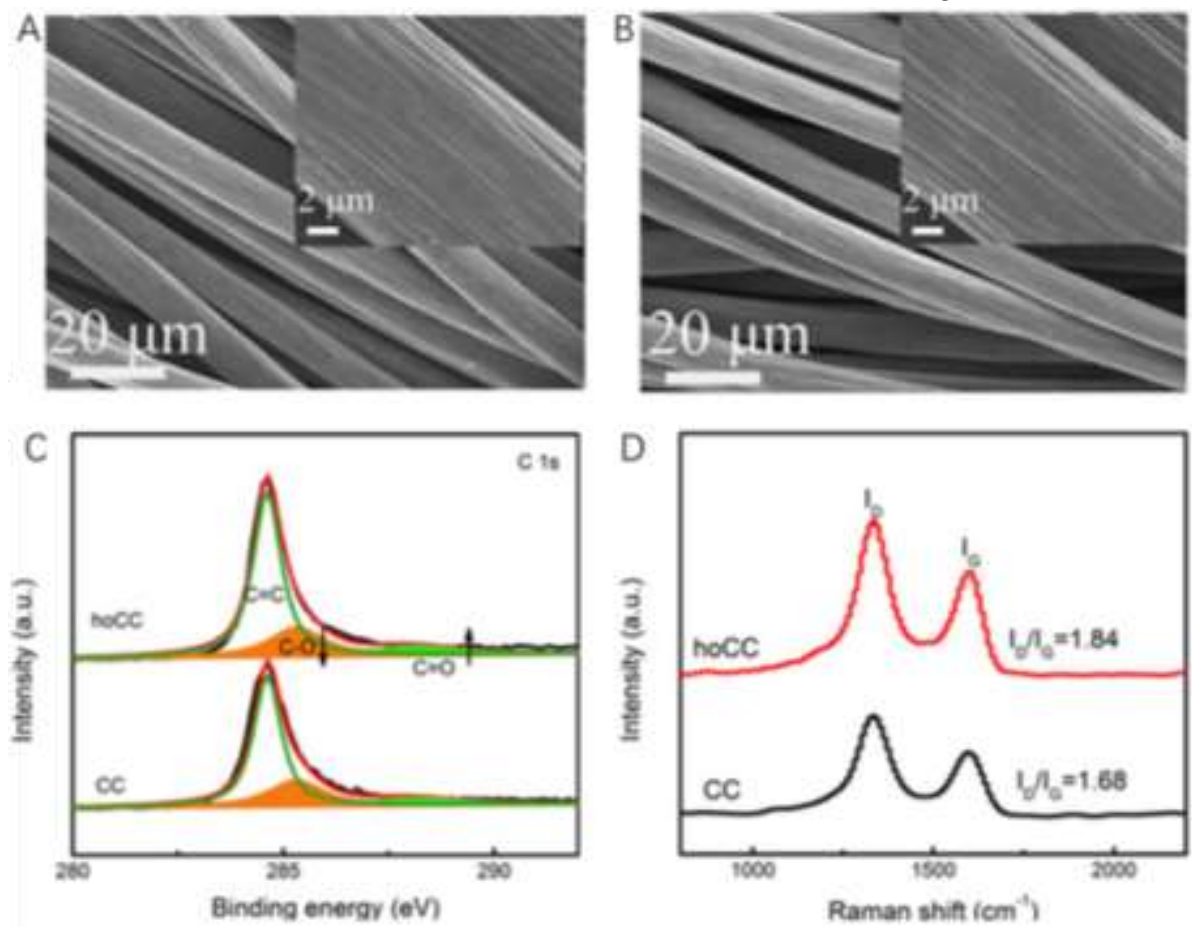

Fig 1: SEM micrographs of (A) CC and (B) hoCC as well as their (C) High-resolution XPS C 1s and (D) Raman spectra

\subsection{Electrochemical performance of the electrode}

For the prepared hoCCE, CV, EIS, DPASV etc. were used to study its electrochemical performance and comparatively analyze it with GCE and CCE.

\subsubsection{Electrochemical behavior of the electrode in $\left[\mathrm{Fe}(\mathrm{CN})_{6}\right]^{3-14-}$}

$\mathrm{CV}$ of hoCCE electrode showed a significantly stronger current than GCE and CCE, indicating that it has better electrochemical performance and higher sensitivity (see Figure 2A).

Figure 2B shows the electrochemical impedance diagrams of hoCCE, GCE and CCE. Where the intersection of the semicircular high-frequency region and the real axis correspond to the ohmic impedance. The intercept of the semicircular low-frequency region with the x-axis represents the external contact resistance. The straight line is due to the diffusion and internal contact resistances of electrolyte ions [10]. As shown in the figure, the

ISSN: 0010-8189

(C) CONVERTER 2020

www.converter-magazine.info 
semicircular impedance (Ret) of GCE, CCE, and hoCCE are $150 \Omega, 100 \Omega$, and $55 \Omega$, respectively. hoCCE has the smallest Ret, indicating that electrons have the fastest transfer rate on the material. The increased surface area translates into a higher adsorption capacity of hoCCE against the ions in the solution, which greatly enhances the electrochemical performance of the sensor.
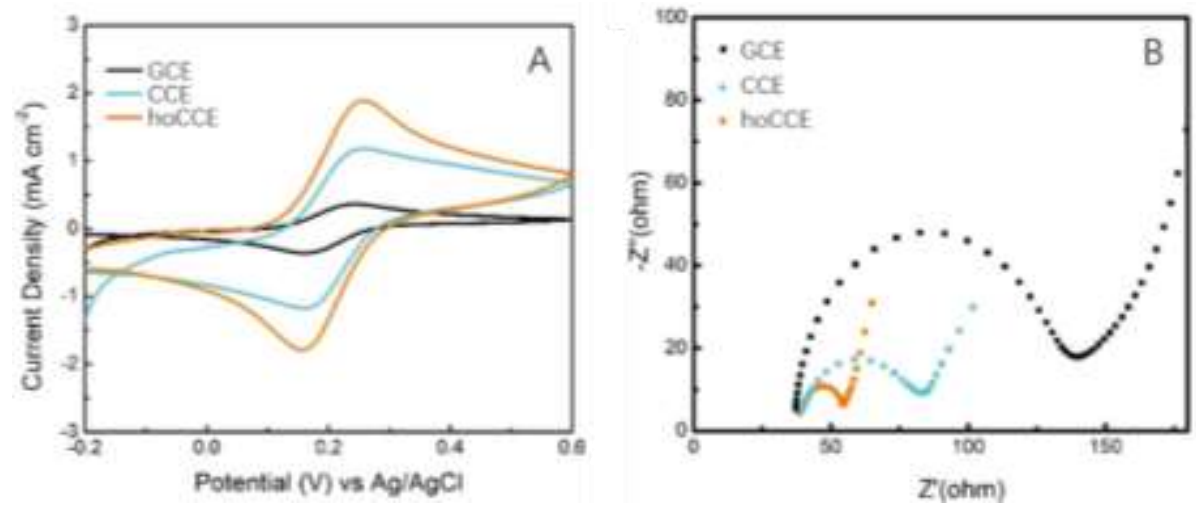

Fig 2: (A) CV (at $50 \mathrm{mV} / \mathrm{s}$ scan speed) and (B) EIS data for the GCE, CCE and hoCCE recorded in $0.1 \mathrm{M}$ $\mathrm{KCl}$ containing $5 \mathrm{mM}$ of $\left[\mathrm{Fe}(\mathrm{CN})_{6}\right]^{3-/ 4-}$

\subsubsection{Scanning speed research}

Figure 3B shows the fitting of the oxidation and reduction peak currents plotted as a function of the square root of the scanning rate $\left(\mathrm{I}_{\mathrm{p}}-\mathrm{V}^{1 / 2}\right)$. Both anode and cathode peak currents obtained for the hoCCE showed linear correlation, which could be expressed as $\mathrm{I}_{\mathrm{pa}}(\mathrm{mA})=0.9612+0.68203 \mathrm{~V}^{1 / 2}$ and $\mathrm{I}_{\mathrm{pc}}(\mathrm{mA})=054061-0.60099 \mathrm{~V}^{1 / 2}$, respectively. The corresponding correlation coefficients $\mathrm{R}$ were equal to 0.9997 and 0.9954 . The linear equations show that the hoCCE cyclic voltammetry peak current value is proportional to the square root of its scanning rate. Therefore, it can be concluded that the electron transfer on the hoCCE surface is mainly affected by the diffusion of the electrolyte solution.
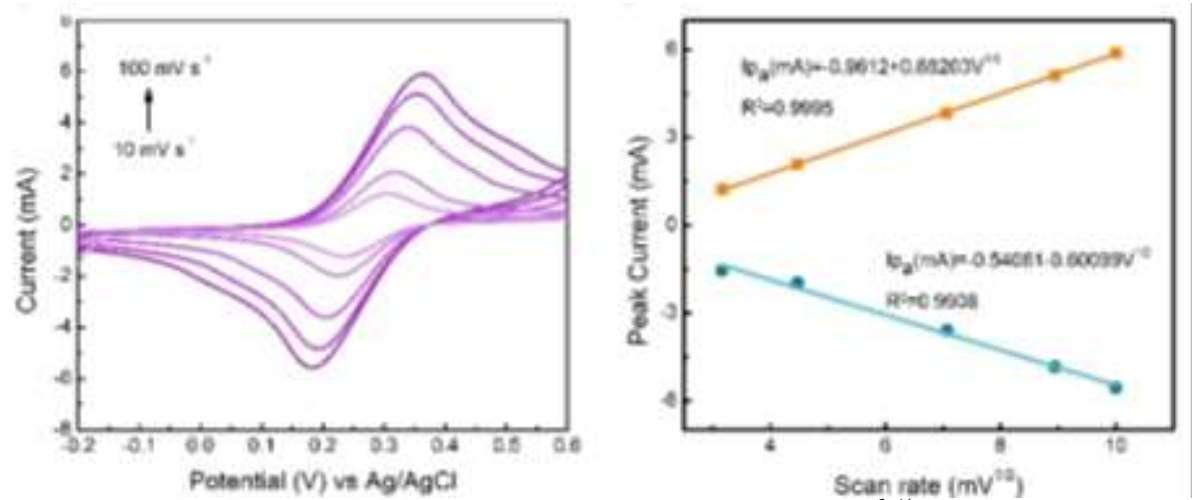

Fig 3: (A) CV diagram of hoCCE in $0.1 \mathrm{M} \mathrm{KCl} \mathrm{containing} 5 \mathrm{mM}\left[\mathrm{Fe}(\mathrm{CN})_{6}\right]^{3-14-}$ at 10, 20, 50, 80, and $100 \mathrm{~m} \mathrm{V \cdot \textrm {s } ^ { - 1 }}$ scan rate from inside out. (B) hoCCE CV peak current plotted as a function of the square root of the scanning rate.

The catalytic performance of the material could be obtained from its active electrochemical area. In the experiment, the electric double-layer capacitance $\left(\mathrm{C}_{\mathrm{dl}}\right)$ of the material is often used for evaluation to determine the number of active sites of the electrode material that actually participate in the reaction. Figure 4A is a set of CV curves obtained in $0.1 \mathrm{M}$ acetate buffer (with $\mathrm{pH}=4.5$ ) at $20-100 \mathrm{mV} \cdot \mathrm{s}^{-1}$ scanning speeds and Figure $4 \mathrm{~B}$ is a fitted curve of the current density difference and scanning speed at a certain potential, the obtained slope of the curve is $\mathrm{C}_{\mathrm{dl}}$. The electrochemically active areas of hoCCE, CCE and GCE are 5.07, 3.87 and $0.17 \mathrm{mF} \cdot \mathrm{cm}^{-2}$ in sequence. It can be seen that hoCCE has a much greater active area than CCE and GCE, indicating that compared with other electrodes, hoCCE has more electrocatalytic active sites, which helps improve the detection performance. 

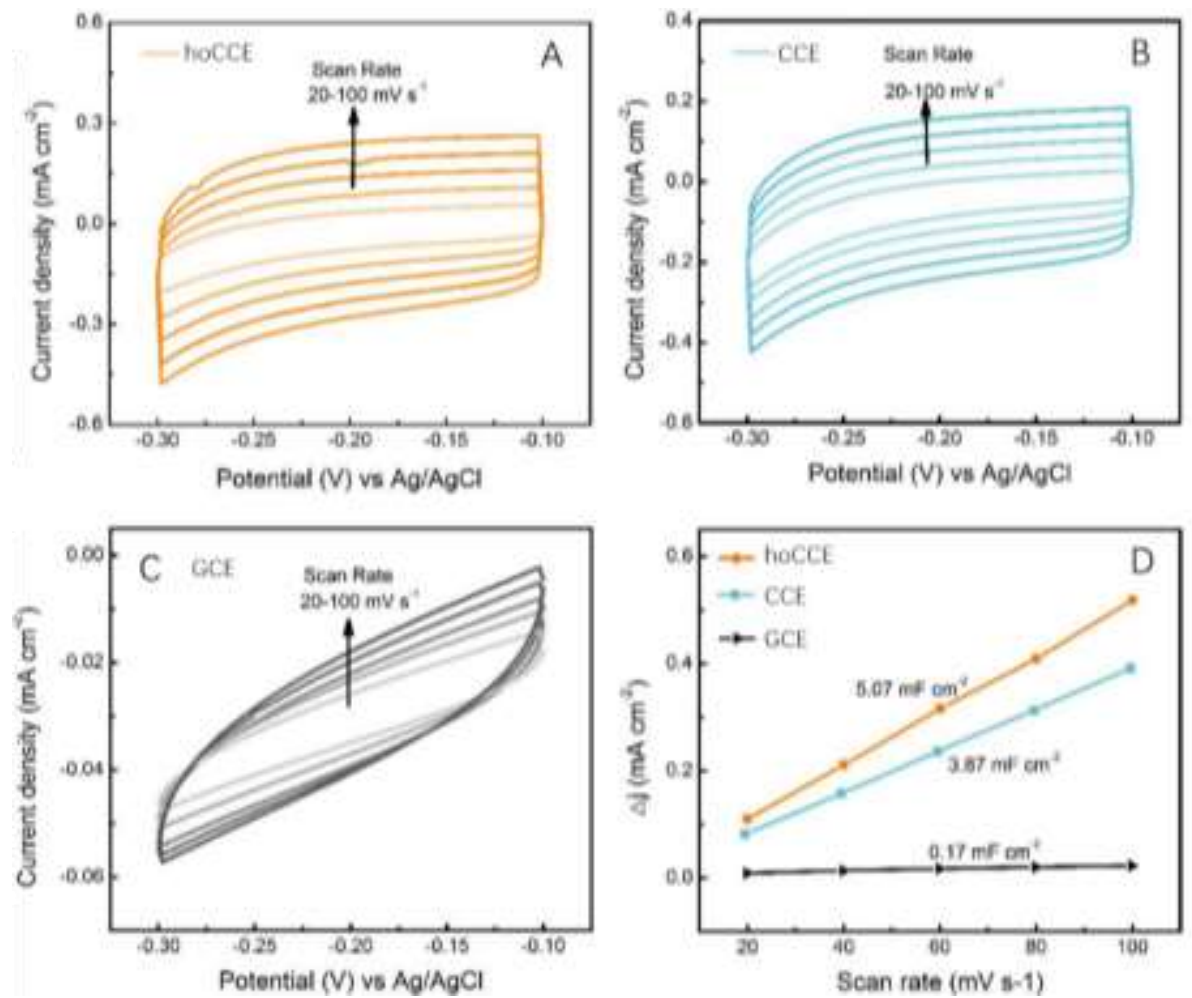

Fig 4: $C V$ diagram of (A) hoCCE, (B) CCE and (C) GCE under different scanning rates (20-100 $\left.\mathrm{mV} \cdot \mathrm{s}^{-1}\right)$; (D) the corresponding $C_{d l}$ value and relative electrochemical active surface area.

\subsubsection{Electrochemical behavior of $\mathrm{Pb}^{2+}$ on the electrode}

In this experiment, differential pulse anodic stripping voltammetry (DPASV) was used to study the electrochemical behavior of GCE, CCE and hoCCE in the presence of $\mathrm{Pb}^{2+}$. The outstanding advantage of anodic stripping voltammetry lies in its high sensitivity. Compared with ordinary voltammetry, its sensitivity can be increased by 2-3 orders of magnitude, which is beneficial for the trace elements' detection. The DPASV is the most sensitive among the current stripping methods, which mainly includes two major steps: in the pre-enrichment stage, the cations in the solution deposits on the working electrode surface under constant potential and agitation; in the dissolution stage, the metal originally deposited on the electrode is oxidized and dissolved out by applying a reverse voltage to generate an oxidation current. In the pre-enrichment process, cations can be deposited on the electrode surface in two ways. First, cations are reduced, followed by their deposition on the working electrode according to the Faraday reaction principle. These cations are then complexed by the modified surface of the working electrode surface, which lowers their valence state, following the principle of adsorption. This experiment was implemented in the first way. Different substances have different dissolution peak potential, and the dissolution peak current presents a certain linear relationship with the concentration of the substance to be tested within a certain range. 


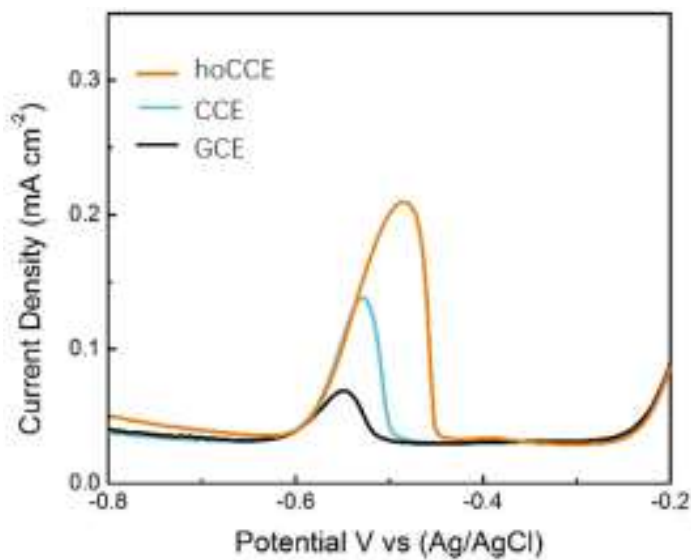

Fig 5: DPASV curves of GCE, CCE and hoCCE in acetate buffer containing $2.0 \mu M \mathrm{~Pb}^{2+}$.

First, a negative voltage is applied to pre-enrich $\mathrm{Pb}^{2+}$ on the working electrode, and then a positive voltage is applied to re-oxidize and dissolve the $\mathrm{Pb}^{2+}$ enriched on the electrode into the solution for detection. Figures 3-5 show the DPASV curves of GCE, CCE and hoCCE in acetate buffer containing $2.0 \mu \mathrm{M} \mathrm{Pb}^{2+}$. As shown in Figure 5, GCE and CCE have very low response to $\mathrm{Pb}^{2+}$, while the modified hoCCE shows a higher oxidation current response. It can be seen that since the modified electrode significantly improves the conductivity and electrochemically active area, its sensitivity in detecting $\mathrm{Pb}^{2+}$ is also greatly enhanced, thus enabling better detection performance.

\subsection{Influence of experimental conditions}

We also analyzed the optimum electrochemical detection condition, namely, $\mathrm{pH}$, deposition potential and time, etc. All optimization tests were performed in the $0.1 \mathrm{M}$ acetate buffer. The optimization was performed by changing the conditions and comparing the electrochemical response of DPASV. The order of the conditions tested (with the $0.1 \mu \mathrm{M} \mathrm{Pb}^{2+}$ as the detection target) was: $\mathrm{pH}$, deposition potential followed by deposition time.

The detected acid-base environment will affect the form of metal ions in the solution. Metal ions tend to be hydrolyzed in a solution with a higher $\mathrm{pH}$ value, which will result in fewer ions enriched on the electrode. At a low $\mathrm{pH}$ value, protons bond with the donor atoms on the electrode surface to reduce the enrichment sites of cations present on the electrode, thereby reducing the response current [11]. Therefore, it is necessary to optimize the solution $\mathrm{pH}$ during detection to ensure the optimal current signal. This study performs detection under $\mathrm{pH}=3.0-6.0$. It is obvious from Figure $6 \mathrm{~A}$ that as the $\mathrm{pH}$ value increases, the current signal first increases and then decreases. At $\mathrm{pH}=4.5$, the current signal reaches the peak value, indicating that in this environment, there is the optimal electrostatic attraction between $\mathrm{Pb}^{2+}$ and carbon cloth. Therefore, the optimal $\mathrm{pH}$ value for detection is set to 4.5.

The deposition potential during ion enrichment also greatly affects the detection effect, and the applied deposition

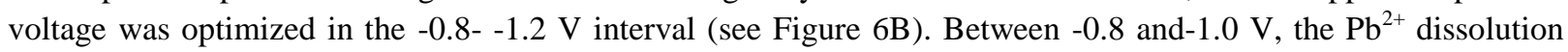
peak current gradually increased with the applied negative voltage, reaching the maximum value at $-1.0 \mathrm{~V}$. Between -1.0--1.2 V, as the applied negative voltage increases, the peak current gradually decreases. At the same time, it was observed in the experiment that the working electrode will produce some small bubbles on the surface when the voltage reaches $-1.1 \sim-1.2 \mathrm{~V}$, indicating that the electrode will undergo hydrogen evolution reaction at this voltage, which generates hydrogen on the surface, reduces the electrode effective working area, which decreases the dissolution peak current. Therefore, it is determined that the optimal $\mathrm{Pb}^{2+}$ deposition potential for detection is $1.0 \mathrm{~V}$.

The deposition time of $\mathrm{Pb}^{2+}$ is also an important influencing condition in the detection process. Under the optimal deposition potential, $\mathrm{Pb}^{2+}$ was enriched for $40 \mathrm{~s}, 80 \mathrm{~s}, 120 \mathrm{~s}, 160 \mathrm{~s}$, and $200 \mathrm{~s}$. As shown in Figure $6 \mathrm{C}$, between $40 \mathrm{~s}$ 
and $120 \mathrm{~s}$, the response current increased rapidly with deposition time, tending to slow down from $120 \mathrm{~s}$ to $200 \mathrm{~s}$, which may be because the deposition of $\mathrm{Pb}^{2+}$ on the electrode surface after $120 \mathrm{~s}$ enrichment is about to reach saturation. Based on the current signal and work efficiency considerations, $160 \mathrm{~s}$ was determined to be the best deposition time.
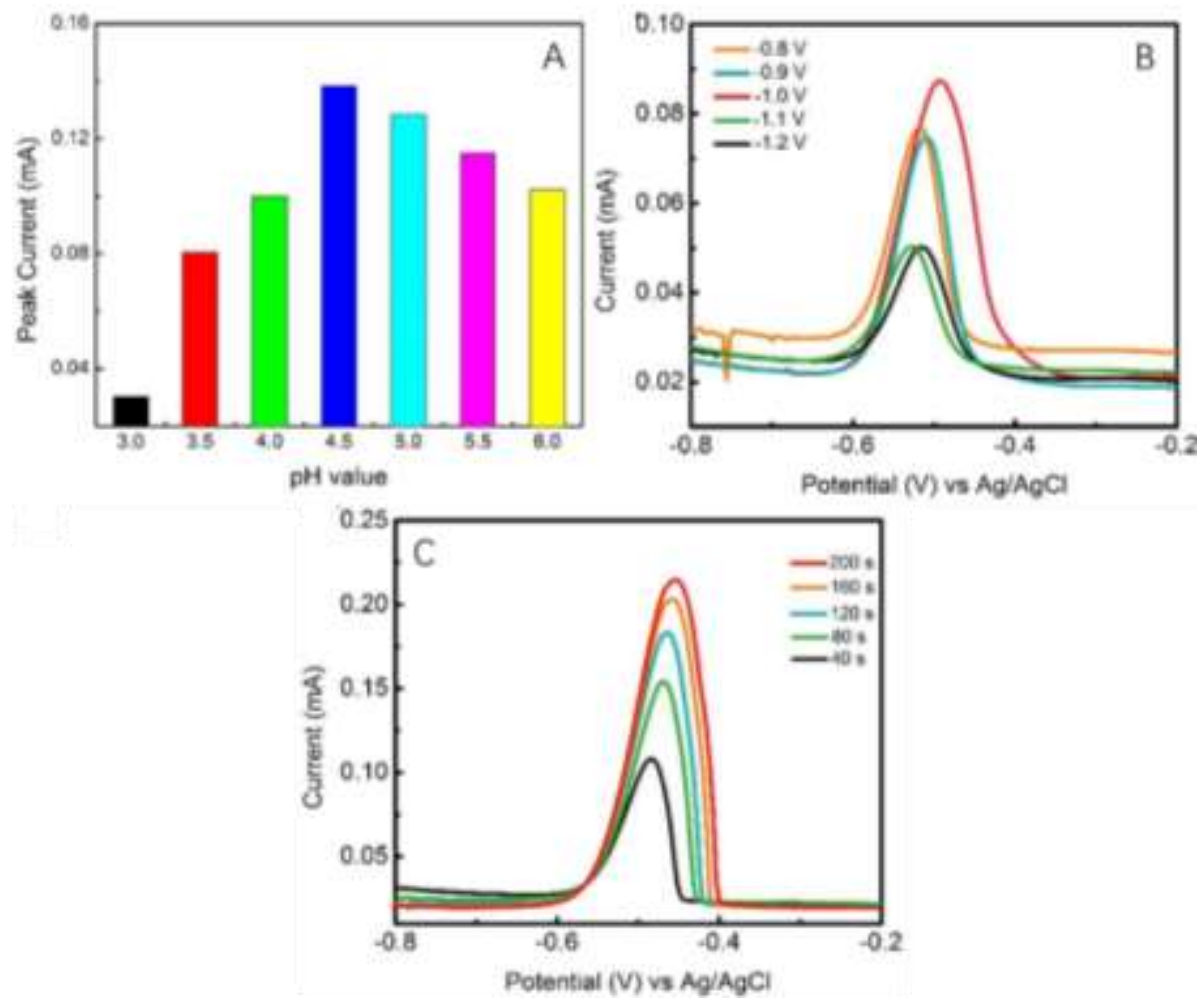

Fig 6: $(A) p H$ and deposition $(B)$ potential and $(C)$ time used during the optimization experiments in $0.1 \mu M P b^{2+}$ acetate buffer

\subsection{Linearity range and detection limit}

Under the optimal conditions, the sensor detects $\mathrm{Pb}^{2+}$ based on the DPASV method. By adding $\mathrm{Pb}^{2+}$ of different concentrations in the solution, record the corresponding DPASV response curve (see Figure 7A). The calibration curve was obtained by using the peak currents at different concentrations $\mathrm{Pb}^{2+}$ concentrations (see Figure 7B). At $\mathrm{Pb}^{2+}$ content equal to $0.06-1.6 \mu \mathrm{M}\left(0.01-0.33 \mathrm{mg} \cdot \mathrm{L}^{-1}\right)$, the peak current has a linear correlation with the $\mathrm{Pb}^{2+}$ concentration, with regression equation $\mathrm{I}(\mathrm{mA})=0.03208+0.12843 \mathrm{C}$, correlation coefficient $\mathrm{R}=0.9996$, limit of detection (LOD) $30 \mathrm{nM}\left(0.006 \mathrm{mg} \cdot \mathrm{L}^{-1}\right)$, and $\mathrm{S} / \mathrm{N}=3$. The calculated sensitivity is $0.13 \mu \mathrm{A} \mu \mathrm{M}^{-1} \cdot \mathrm{cm}^{-2}$.

We also compared the performance of other electrodes with ours for the $\mathrm{Pb}^{2+}$ detection (see Table 1). Although the sensor constructed in this study has a relatively high LOD, for groundwater pollution investigations, the detection object is often a sample suspected of contamination, and a too low detection limit is of little significance. What's important is that the linear range of the sensor has certain advantages compared with many studies. At the same time, the simple modification operation, the lower cost, and the strong flexibility characteristics are more practical in the field application. 

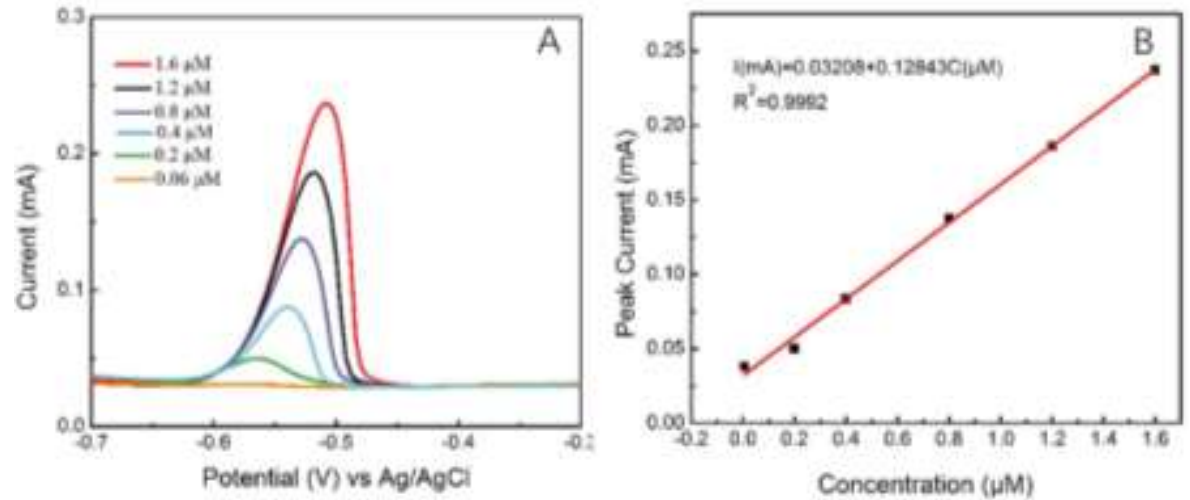

Fig 7: (A) Voltammogram and (B) calibration curve of $\mathrm{Pb}^{2+}$ at different concentrations (0.06-1.6 $\left.\mu M\right)$ in DPASV measurement.

Table 1 Comparison for the $\mathrm{Pb}^{2+}$ detection with previous reports

\begin{tabular}{|c|c|c|c|}
\hline electrode materials & linear range $(\mu \mathrm{M})$ & LOD $(\mathrm{nM})$ & references \\
\hline $\mathrm{Au} / \mathrm{rGOCNT/Bi}$ & $0.01-1$ & 1 & {$[8]$} \\
\hline Pd/PAC & $0.5-8.9$ & 67 & {$[9]$} \\
\hline PDMS & $0.05-0.4$ & 6 & {$[10]$} \\
\hline G/PANI/PS & $0.05-2.4$ & 16 & {$[11]$} \\
\hline hoCC & $0.06-1.6$ & 30 & This work \\
\hline
\end{tabular}

\subsection{Stability and anti-interference tests}

The electrode performance reproducibility was determined by continuously scanning the DPASV curve 25 times under the optimum conditions. The standard deviation of the calculated DPASV peak current values in 25 times is $3.7 \%$. In addition, under the same experimental conditions, the DPASV test was performed on 6 identical $\mathrm{Pb}^{2+}$ sensors as shown in Figure 3-8A, and the relative standard deviation of the obtained peak current was about $4.2 \%$. It suggests that the sensor has good reproducibility. At the same time, when measuring the sensor after placement at room temperature for 7 days, the peak current is $92 \%$ of the initial value, indicating that the sensor has good stability.

Whether the electrochemical sensor is good or not depends on whether it has a special selectivity against the measured ions, that is, anti-interference. To this end, $\mathrm{Na}^{+}, \mathrm{K}^{+}, \mathrm{Zn}^{2+}, \mathrm{Co}^{2+}, \mathrm{Ni}^{2+}, \mathrm{Cd}^{2+}, \mathrm{Fe}^{3+}$ were used as interfering ions, and the DPASV curve without any ions was used as a control. The DPASV peak current of $10 \mu \mathrm{M}$ interfering ions as above was measured under the optimum experimental conditions. Simultaneously, we compared it with the DPASV curve of $1 \mu \mathrm{M} \mathrm{Pb}^{2+}$ to determine the DPASV peak current value of $10 \mu \mathrm{M}$ interfering ions in the sensor containing $1 \mu \mathrm{M} \mathrm{Pb}^{2+}$, as shown in Figure 8B. There is slight difference between the peak current values of $10 \mu \mathrm{M}$ interfering ions measured in two times, which is much lower than the peak current value of $1 \mu \mathrm{M} \mathrm{Pb}{ }^{2+}$, indicating that even when the interfering ion concentration is 10 times of the $\mathrm{Pb}^{2+}$ concentration, the sensor still has good selectivity against $\mathrm{Pb}^{2+}$ and superior anti-interference performance. 

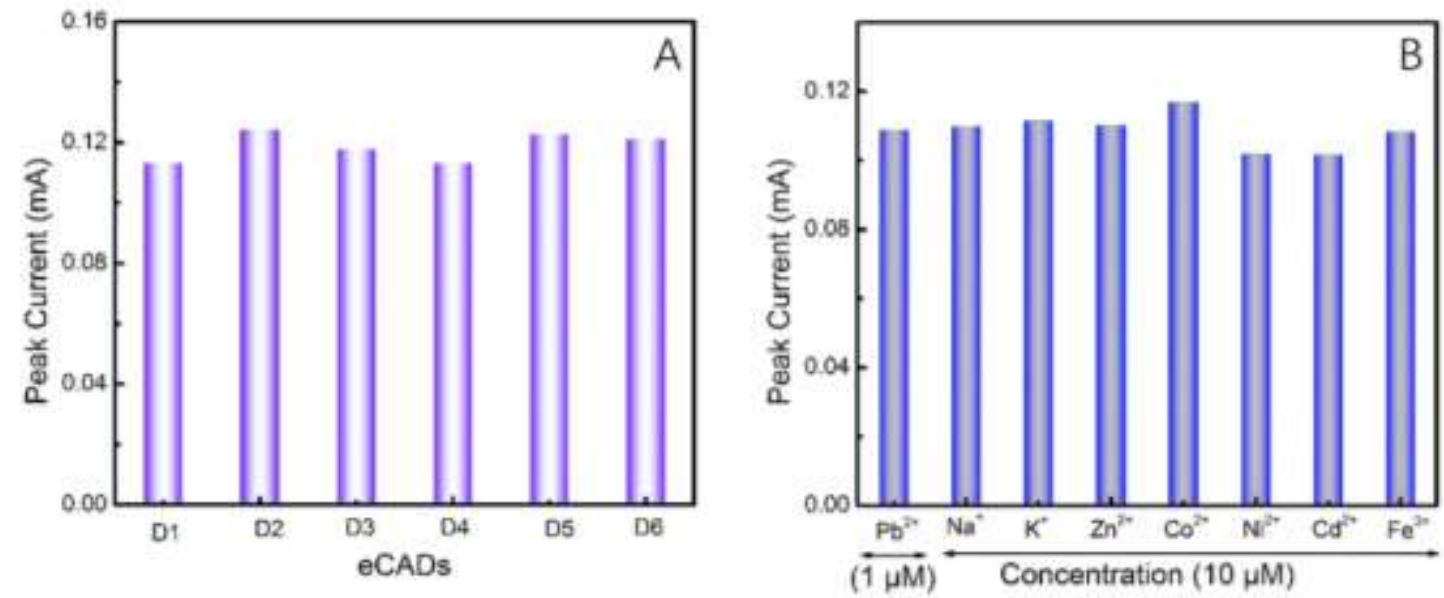

Fig 8: (A) Sensor (A) stability and (B) interference test.

\subsection{Sample testing}

To prove the actual detection ability of the electrochemical sensor, 4 sets of samples were taken from the sewage canal of an industrial park in Xi'an for actual detection. After the sample was passed through a $0.45 \mu \mathrm{m}$ filter, its $\mathrm{pH}$ was modified to 4.5 using the acetate buffer solution. Then, add standard solutions with various $\mathrm{Pb}^{2+}$ contents to the samples, and use the "standard addition method" for detection. The data shown in Table 2 indicates that the RSD value is between $2.7 \%-3.8 \%$, and the recovery rate is $98 \%-107 \%$. At the same time, for comparison, $\mathrm{Pb}^{2+}$ concentration was detected by ICP-AES in each water sample. The electrochemical sensor has basically the same detection results as ICP-AES. Therefore, the $\mathrm{Pb}^{2+}$ detection sensor supports actual detection.

Table 2 Determination of $\mathrm{Pb}^{2+}$ in the water sample using standard addition method

\begin{tabular}{|c|c|c|c|c|c|c|}
\hline Sample & Added $(\mu \mathrm{M})$ & Found $(\mu \mathrm{M})$ & $\begin{array}{l}\text { Determined } \\
(\mu \mathrm{M})\end{array}$ & Recover $(\%)$ & $\operatorname{RSD}(\mathrm{n}=3, \%)$ & $\begin{array}{c}\text { ICP-AES } \\
(\mu \mathrm{M})\end{array}$ \\
\hline 1 & $\begin{array}{l}0.1 \\
0.2 \\
0.3\end{array}$ & $\begin{array}{l}0.36 \\
0.47 \\
0.58\end{array}$ & 0.26 & $\begin{array}{l}101 \\
102 \\
106\end{array}$ & $\begin{array}{l}3.5 \\
3.3 \\
3.8\end{array}$ & 0.25 \\
\hline 2 & $\begin{array}{l}0.1 \\
0.2 \\
0.3\end{array}$ & $\begin{array}{l}0.66 \\
0.78 \\
0.86\end{array}$ & 0.57 & $\begin{array}{c}98 \\
101 \\
99\end{array}$ & $\begin{array}{l}3.1 \\
3.0 \\
2.7\end{array}$ & 0.59 \\
\hline 3 & $\begin{array}{l}0.1 \\
0.2 \\
0.3\end{array}$ & $\begin{array}{l}1.19 \\
1.21 \\
1.38\end{array}$ & 1.03 & $\begin{array}{c}105 \\
98 \\
104\end{array}$ & $\begin{array}{l}2.7 \\
2.9 \\
3.4\end{array}$ & 1.00 \\
\hline 4 & $\begin{array}{l}0.1 \\
0.2 \\
0.3\end{array}$ & $\begin{array}{l}1.32 \\
1.45 \\
1.59\end{array}$ & 1.21 & $\begin{array}{l}101 \\
103 \\
107\end{array}$ & $\begin{array}{l}2.8 \\
3.2 \\
3.6\end{array}$ & 1.23 \\
\hline
\end{tabular}

\section{Conclusions}

A hoCCE electrochemical sensor for detecting $\mathrm{Pb}^{2+}$ was prepared by simple high-temperature hydrothermal treatment modification of carbon cloth. The sensor electrochemical activity for $\mathrm{Pb}^{2+}$ detection was studied by $\mathrm{CV}$, EIS, DPASV, etc., under the optimized $\mathrm{pH}$ and deposition potential and time values of the detection solution. The stability and anti-interference tests were carried out. The experimental results show that hydrothermal treatment of carbon cloth surface increases the ketone-based sites and the degree of defects, adds the electrochemically active area, conductivity and detection sensitivity, and boosts the catalytic performance of $\mathrm{Pb}^{2+}$. The current concentration curves were obtained using the DPASV method under the optimum conditions. The linear range was determined as 
$0.06-1.6 \mu \mathrm{M}\left(0.01-0.33 \mathrm{mg} \cdot \mathrm{L}^{-1}\right)$, regression equation $\mathrm{Ip}(\mathrm{mA})=0.03208+0.12843 \mathrm{C}(\mu \mathrm{M}), \mathrm{R}=0.9996, \mathrm{LOD}=30$ $\mathrm{nM}\left(0.006 \mathrm{mg} \cdot \mathrm{L}^{-1}\right), \mathrm{S} / \mathrm{N}=3$, sensitivity $0.13 \mu \mathrm{A \mu} \mu \mathrm{M}^{-1} \cdot \mathrm{cm}^{-2}$. The sensor was also applied to test $\mathrm{Pb}^{2+}$ in actual water. Compared with previous research reports, hoCCE demonstrates advantages in linear interval detection, cost, preparation procedure, and vulnerability. This study provides an effective method for detecting $\mathrm{Pb}^{2+}$ in water, and also extends the application of carbon cloth modified electrodes in electrochemical sensors.

\section{Acknowledgments}

We would like to express our gratitude to the China Geological Survey for their financial assistance through the grants number DD20160308 and DD20190331.

\section{References}

[1] García-Alixa, F.J. Jimenez-Espejoa, J.A. Lozanoa, G. Jiménez-Morenob, F. Martinez-Ruiza, L. García Sanjuánc, G. Aranda Jiménezd, E. García Alfonsoe, G. Ruiz-Puertasf and R. Scott Andersong, "Anthropogenic impact and lead pollution throughout the Holocene in Southern Iberia", in Distributed Science of The Total Environment, vol. 449, pp. 451-460, 2013.

[2] A.A. Bogush, J.A. Stegemann and A. Roy, "Changes in composition and lead speciation due to water washing of air pollution control residue from municipal waste incineration", in Distributed Journal of Hazardous Materials, vol. 361, pp. 187-199, 2019,

[3] D. Absalon and B. Ślesak, "The effects of changes in cadmium and lead air pollution on cancer incidence in children", in Distributed Science of The Total Environment, vol. 408, no. 20, pp. 4420$4428,2010$.

[4] J. García-Lestón, J. Méndez, E. Pásaro and B. Laffon, "Genotoxic effects of lead: An updated review", in Distributed Environment International, vol. 36, no. 6, pp. 623-636, 2010.

[5] A.M. Safruk, E. McGregor, M.L. Whitfield Aslund, P.H. Cheung, C. Pinsent, B.J. Jackson, A.T. Hair, M. Lee and E.A. Sigal, "The influence of lead content in drinking water, household dust, soil, and paint on blood lead levels of children in Flin Flon, Manitoba and Creighton, Saskatchewan”, in Distributed Science of The Total Environment, vol. 593-594, pp. 202-210, 2017.

[6] Y. Lu, Z. Shi and Q. Liu, "Smartphone-based biosensors for portable food evaluation", in Distributed Current Opinion in Food Science, vol. 28, pp. 74-81, 2019.

[7] A. Waheed, M. Mansha and N. Ullah, "Nanomaterials-based electrochemical detection of heavy metals in water: Current status, challenges and future direction", in Distributed Trac Trends in Analytical Chemistry, vol. 105, pp. 37-51, 2018.

[8] W. Qiu, H. Xiao, Y. Li, X. Lu and Y. Tong, "Nitrogen and Phosphorus Codoped Vertical Graphene/Carbon Cloth as a Binder-Free Anode for Flexible Advanced Potassium Ion Full Batteries", in Distributed Small, vol. 15, no. 23, pp. 1901285, 2019.

[9] X. Lu, W.L. Yim, B.H.R. Suryanto and C. Zhao, "Electrocatalytic Oxygen Evolution at SurfaceOxidized Multiwall Carbon Nanotubes", in Distributed Journal of the American Chemical Society, vol. 137, no. 8, pp. 2901-2907, 2015.

[10] W. Zhang, H. Zhang, S.E. Williams and A. Zhou, "Microfabricated three-electrode on-chip PDMS device with a vibration motor for stripping voltammetric detection of heavy metal ions", in Distributed Talanta, vol. 132, pp. 321-326, 2015.

[11] N. Promphet, P. Rattanarat, R. Rangkupan, O. Chailapakul and N. Rodthongkum, "An electrochemical sensor based on graphene/polyaniline/polystyrene nanoporous fibers modified electrode for simultaneous determination of lead and cadmium", in Distributed Sensors and Actuators B: Chemical, vol. 207, pp. 526-534, 2015. 